\title{
Towards a prioritization of needs to support decision making in organizational change processes
}

\author{
Alexander Kaiser \\ Vienna University of \\ Economics and Business \\ alexander.kaiser@wu.ac.at
}

\author{
Florian Fahrenbach \\ Vienna University of \\ Economics and Business \\ fahrenbach@ai.wu.ac.at
}

\author{
Florian Kragulj \\ Vienna University of \\ Economics and Business \\ kragulj@ai.wu.ac.at
}

\author{
Thomas Grisold \\ Vienna University of \\ Economics and Business \\ grisold@ai.wu.ac.at
}

\begin{abstract}
The purpose of this paper is to introduce a decision support system to prioritize needs that are anchored in an organization. We build on a systems-thinking approach and develop a weighted additive index which considers different viewpoints of organizational stakeholders. First, we briefly review the literature about identifying and prioritizing needs from various scientific disciplines. Then, we use boundary critique to identify critical stakeholders that lead to three different viewpoints in the decision support system. The internal view reflects needs that members of the organization find important and urgent to be satisfied. The external view considers knowledge of outsiders, i.e. who do not work in the organization but are acquainted with it (e.g. experts, customers, facilitators). The systemic view considers system inherent interrelations of needs as perceived by decision makers in the organization. These stakeholder views get assessed by different dimensions, which are subsequently combined and weighted. Based on a method to identify needs, we apply this index in an case study conducted in Austria and discuss implications for theory and practice.
\end{abstract}

\section{Introduction}

\subsection{Needs - identification and prioritization}

Needs are motivational forces that set us in motion and cause our acting. They can have a significant impact on innovation [1]-[7], decision making [8], [9] and organizational learning processes [7], [10], [11] such as strategy or vision development. Explicit knowledge about needs and developing capacities to address them is crucial for all kinds of organizations.

To identify needs, several approaches have been discussed in the literature [7], [12]-[15]. However, this is only one side of the coin. We also have to know, which need outpaces the other and where to start allocating limited time and resources, i.e. we have to prioritize them. In general, decision makers seem overwhelmed by the number of possible starting points to trigger organizational learning processes. This observation is in line with economic decision theory, stating that the willingness to perform an action decreases when the number of options increases. This so-called "paradox of choice" could be overcome if people have a well-defined and limited set of options [16].

Scientific disciplines, such as philosophy, psychology, marketing, social-politics make use of the concept of needs with different definitions [17], [18] and consequently, their prioritization changes. Regarding psychology, the most prominent account that includes a prioritization of needs is Maslow's hierarchy of needs [19], [20]. In the socio-political discourse, a prioritization of needs is derived from the harm it causes if it remains unsatisfied [14], [21]-[23]. When needs are defined as instrumental necessity for a purpose as in marketing [13], [24] or software development [25], specific methods like conjoint analysis [26], quality function deployment [26] or the house of quality [27], [28] can be used for prioritization.

In the field of organization studies and innovation, von Hippel and von Krogh [6] recently took up the idea and proposed a model in which they implicitly assume a prioritization of needs. According to their view, a need can be uncovered simultaneously when we find a corresponding solution. To evaluate whether a solution corresponds with an underlying need, we form viable 'need-solution pairs'. In their model, two three-dimensional landscapes represent solutions and needs. In case of a viable connection between a point on the need and solution landscape, an arrow refers to a need-solution pair. However, the authors stay conceptually and do not propose a method to actually identify and prioritize needs or solutions, which would be crucial for establishing both landscapes and their correspondence.

We build on the common assumption that needs, i.e. an agent's necessities towards a purpose, are discovered before the intentional design of satisfiers. 
While needs refer to the agent itself, satisfiers reflect concrete solutions (e.g. products, processes, services) which satisfy specific needs. Their relation reads as one-to-many; for instance, the need for mobility can be satisfied in many different ways (e.g. buying a car, renting a bicycle, taking the train).

\subsection{Research gap and method}

Taking up the idea of von Hippel and von Krogh's simultaneous discovery of need-solution pairs but taking up the idea of a need-landscape, it seems to be crucial to identify and prioritize the most important needs which have the strongest sustainable impact on a system. From our point of view it is plausible to start with needs and intentionally narrow the space for subsequent search for solutions [29], [30]. Consequently, the main research gap is the lack of methods to prioritize salient needs within a social system to enable informed search for satisfiers and solutions within action research projects [7], [31]. Accordingly, the research question is:

How to prioritize needs in a social system in order to guide effective need-satisfaction strategies?

The main focus of this paper is to contribute to the ongoing and multidisciplinary debate regarding the prioritization of needs [9], [22], [32]-[34]. We propose a weighted additive index [35], [36] that prioritizes needs from a systems science perspective and serves as a decision support system [37], [38] in organizational learning processes (e.g. company, municipality).

To answer the research question, we conducted a multidisciplinary literature review to build the ground for explorative analysis and theoretical foundation. Following a case study design [39], we tested the proposed additive weighted index in an empirical project where we gained first experiences. The research provided ecologically valid data to redefine and adapt the weighted additive index [40], [41].

The remainder of the paper is structured as follows. In section 2, we argue that a systems-thinking perspective is beneficial to identify and prioritize needs for organizational learning. We outline a method to identify needs (Bewextra) and establish crucial stakeholder-roles. In section 3, we outline a weighted additive index for the prioritization of previously identified needs in a social system and apply it to Bewextra. In section 4, we present empirical findings from a case study with an institute of the Austrian Federal Economic Chamber in which we applied the method. Finally, we discuss the findings and present limitations of the decision support system as well as implications for further research.

\section{Using a systems thinking approach to identify and prioritize needs}

In order to provide a holistic framework to identify as well as prioritize needs anchored in an organization we take a systems thinking perspective. As opposed to reductionist perspectives, systems thinking observes phenomena in their entirety. It takes into account the relationships within a system, between systems and between the system and its environment [42]-[44]. The importance of systems thinking has been recognized in knowledge management [45] and in this article, we apply it to guide prioritization of needs within organizational learning processes. A systems thinking perspective must consider interactions and relationships between parts of an organization in order to understand it as an entity, how it functions and what it does [46]. This enables us to see the organization as part of a whole [42], [47], [48]. To do so, we have to take into account who is in the system. An organization is defined by what its members think it is and its identity is also constructed by external entities, i.e. the environment [49]. Identifying knowledge about needs, which could contribute to the organization's capacity to innovate, cannot only be identified by its members but has to consider what outsiders think because the system itself cannot fully understand the complexity of its environment [47], [49].

In order to apply systems thinking within a project context, we must define what the system is and clarify the boundary conditions of the system within which it is operationally closed [50], [51], [52]. The concept of boundaries lies also at the heart of identifying stakeholders. Here, we build on critical system heuristics [53]. According to Midgely, boundary critique is normative and touches upon ethical questions: "boundaries define both what issues are to be included, excluded, or marginalized in analyses and who is to be consulted or involved" [54]. Achterkamp and Vos [55] adapted the approach to define critical stakeholders within project contexts such as organizational learning. They state "identifying stakeholders means that a line is drawn between parties to be involved and parties not to be involved". A stakeholder is "any group or individual who can affect or is affected by the achievement of the organization's objectives" [56], [57]. Whereas Ulrich and Reynolds [53] distinguish between the involved and the affected, Achterkamp and Vos [55] differentiate between the actively involved and passively involved.

Based on three sources of influence, Ulrich [58] furthermore distinguishes three crucial roles that stakeholders can take which can be established using 
specific questions. Asking: “whose purposes (values, interests) are being (ought to be) served?" Answering this question for a project leads to the sources of motivation and the role of the client. Asking: "who has (ought to have) the power to decide?" Answering this question for a project leads to the sources of control and the role of the decision maker. Asking: "who contributes (ought to contribute) the necessary expertise?" Answering this question within a project leads to the sources of expertise and role of the planner.

\subsection{A method to identify needs}

To identify needs for prioritization, we use Bewextra, a method which premises rely on systems thinking. Bewextra has been presented for the first time at the HICSS-47 conference and consists of three consecutive steps [7], [10] (see figure 1). The first step, 'Bewextra-Collect' uses a "learning from the future" approach to acquire satisfiers (reported ideas, dreams and wishes of participants) [59], [60]. The second step, 'Bewextra-Analytic', uses an abductive reasoning and a haptic clustering approach, based on grounded theory [61], [62] to generate hypothesis about needs. The third step, 'Bewextra-Validation', uses communicative validation to validate the need hypothesis by system members.

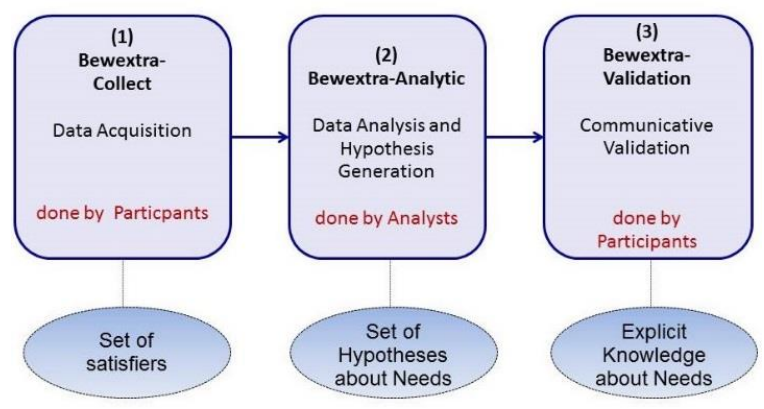

Figure 1: Bewextra framework

Bewextra helps to explicate the shared needs of organizational members, which would otherwise remain unknown and hidden to the system itself. It follows the main assumption that knowledge about needs increases an organizations potential to initiate learning or transformation processes. Normally, we are used to take actions with respect to satisfiers, in other words, known artefacts that have proven successful in the past. However, need knowledge is one level beneath and yields more potential to develop new and innovative solutions [7]. Bewextra has been applied in different projects covering various domains [7], [11], [63]

\subsection{Prioritizing needs - establishing views}

Based on previously identified stakeholder-roles and a systems perspective, a prioritization of needs should include at least three different views of a system [58], namely:

1. an internal view $(I)$ of the system. It is the overall view of organizational members. The individuals affected by a project prioritize selected needs according to their perspective.

2. an external view $(E)$ of the system. It is the overall view of individuals who are not member of the organizations but gained experience with during the process of contributing to such a project. This view can be assessed by facilitators, analysts, clients and experts.

3. a systemic view $(S)$ which analyses the relation of needs in a network. It is assessed by decisionmakers in an organization as they know the organization as a whole. A need is perceived as more potential if it contributes to the satisfaction of other needs as well.

These three views refer to three dimensions of the weighted additive index. Each of these dimensions is determined by several influencing factors. In the following section, we describe these three dimensions and their influencing factors in detail and apply them to Bewextra.

\section{Three views to prioritize needs}

We apply the concept introduced before to the methodological framework Bewextra (see section 2.1). We propose a weighted additive index for each need of a catalogue of needs identified in BewextraAnalytic. The index shows the relative importance of a need in a system and serves as a decision support system. In the context of Bewextra, we refer to this index as the Bewextra Need Priority Index (BNPI).

\subsection{Internal view of the system}

The internal-view of a system assesses the importance and relevance of a need from the viewpoint of organizational members. There are three relevant factors to consider:

1. It should be validated whether a need is shared by the majority of the organization's members. When a need is accepted by a majority of members, it becomes a shared need. We denote the acceptance rate as $I_{0}$.

2. We have to consider the importance of each need from the point of view of each organizational member. The higher the aggregated rating of importance of a need, the more important it is to develop satisfiers. This factor is denoted as $I_{l}$ 
3. It is necessary to consider the current level of need satisfaction. The lower the current level of need satisfaction of each validated need from the viewpoint of each member of the system, the more urgent it is to consider this need when developing satisfiers or solutions. This factor is denoted as $I_{2}$.

$I_{0}, I_{l}$ and $I_{2}$ depict the acceptance rate, the ranking of needs in relation to the importance and how urgent it is to satisfy a need from an internal point of view.

This can be applied to Bewextra using an extended version of the online questionnaire within the step of Bewextra-Validation. Here, we can collect concrete values for $I_{0}, I_{l}$ and $I_{2}$. While $I_{0}$ reflects the acceptance rates of the need hypotheses, $I_{l}$ can be computed by the aggregation of the rankings of importance of each accepted hypothesis for each member of the system. $I_{2}$ can be computed by using a scaling question (1 to 10) for each need, where 10 means that this need is currently fully satisfied and 1 means that this need is not satisfied at all.

\subsection{External view of the system}

To avoid blind spots and to investigate needs holistically, an external view $(E)$ is included. It reflects the perception of experts who are familiar with the system but nevertheless externals. However, a profound relationship between externals and the organization is necessary. Candidates for such an external assessment include, for example, customers, facilitators, analysts or other experts.

The external view is based on data accessible for externals. This can be data gathered in long-term interactions with the organization, such as experiences of partners, customers, retirees, or (short-term) selective in-depth data, such as experiences of facilitators who worked with the organization.

In order to implement the external view for the Bewextra framework, we use two sets of data that we generate while we conduct the Bewextra process in an organization. On the one hand, we exploit the personal impressions and experiences of the researchers and data analysts, and on the other hand, we incorporate (quantifiable) data that we generate during BewextraAnalytic.

To apply the external view in a Bewextra-process, we assess two values. First, $E_{1}$ reflects the relative importance of validated needs of the social system with respect to how externals see them. Here, we ask non-members (e.g. analysts, facilitators) to rank the needs within the system according to the relative importance they estimate. We choose a more complex approach to include the second set of data $\left(E_{2}\right)$. In Bewextra-Analytic, analysts organize the codes, which were gathered in Bewextra-Collect, as clusters. Need categories emerge from those clusters. The aim of the interpretative task of clustering is to find semantically coherent patterns. Clusters should be coherent in themselves and distinct from other clusters. Clusters are shaped like a table and organized as follows: Columns represent distinct aspects of the same need category, while rows represent codes assigned to the same need aspect (see figure 2).

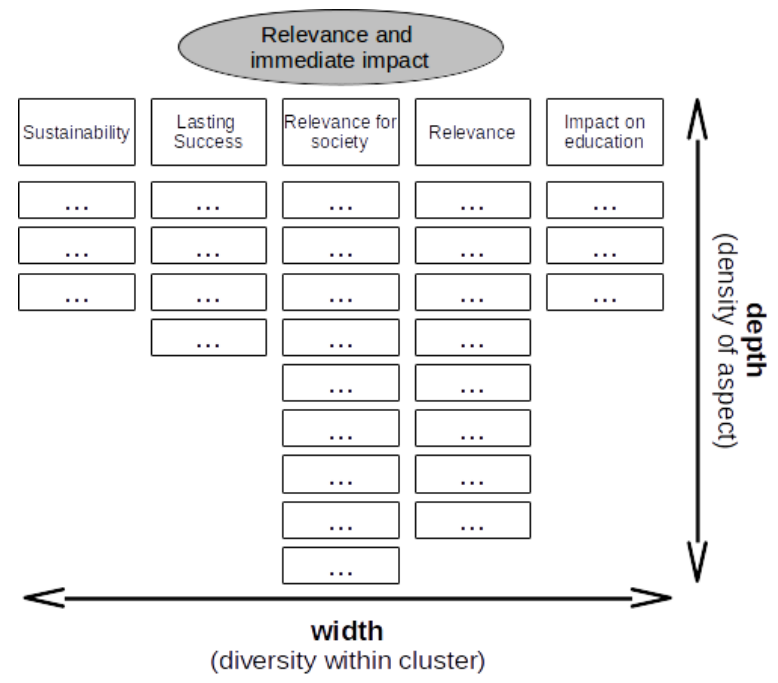

Figure 2: Structure of need clusters (example "relevance and immediate impact")

As a result, a 'wide' but hardly 'deep' cluster represents a need category which is of little density but high diversity. In favour of prioritizing 'wide' clusters, one could argue that these reflect wide ranges of aspects to be satisfied. However, in contrast, we could also argue that 'deep' clusters reflect a very prevailing need since many indications are assigned to a single cluster/need aspect. Since we think both perspectives are worth considering, we include the relative 'wide' as well as the relative 'depth' of a cluster into the measure $E_{2}$ and weight them equally $(\alpha$ and $\beta) . E_{2}$ reads as follows:

$$
E_{2}=\alpha * \frac{\text { width }}{\text { avg.width }}+\beta * \frac{\text { avg.depth of the cluster }}{\text { avg.depth of all clusters }}
$$

\subsection{Systemic view of the system}

The systemic view $(S)$ refers to the inherent relation of needs in a network. Knowledge about interactions and dependencies of needs can be explicated. This view assesses how the satisfaction of one need changes the satisfaction of another need: If satisfaction of need 1 changes, how would that influence the satisfaction of need 2? The systemic view uses a Cross-Impact-Matrix (CIM) [64], [65]. 
This method is widely used in long range-planning, future studies and management studies [66]. It is a "tool for systematic description of all potential modes of interaction between a given set of variables and the assessment of the strength of these interactions" [66]. Assessing the relation of needs in a network is a tedious task and requires deliberate effort which goes beyond "day-to-day" business.

The CIM assesses the impact of one need on another. This impact can be (subjectively) rated as non-existent (0) weak (1), medium (2) or strong (3). The role of each need is depicted as an active-sum (sum of the rows), i.e., how strong one need influences the whole systems, as well as a passive sum (sum of the columns) which indicates how sensitive a need is when changing the whole system [66]. An example is given in table 1 .

\begin{tabular}{|c|c|c|c|c|c|}
\hline \multicolumn{6}{|l|}{ CIM } \\
\hline & $\begin{array}{l}\text { Need } \\
1\end{array}$ & $\begin{array}{l}\text { Need } \\
2\end{array}$ & $\ldots$ & $\begin{array}{l}\text { Need } \\
\mathbf{N}\end{array}$ & $\begin{array}{l}\text { Acti } \\
\text { ve- } \\
\text { sum }\end{array}$ \\
\hline Need 1 & & 1 & $\ldots$ & 0 & 1 \\
\hline Need 2 & 2 & & $\ldots$ & 3 & 5 \\
\hline ... & $\cdots$ & $\ldots$ & & $\ldots$ & $\ldots$ \\
\hline Need $\mathbf{N}$ & 1 & 0 & $\ldots$ & & 1 \\
\hline $\begin{array}{l}\text { Passive- } \\
\text { sum }\end{array}$ & 3 & 1 & $\ldots$ & 3 & 7 \\
\hline
\end{tabular}

Table 1: Exemplary scheme of a CIM

To gain knowledge about the active or reactive character of a need and to find possible leverages and steering potentials of them, we calculate the relation between the active sum and the passive sum. The quotient $\left(\frac{\text { active sum }}{\text { passive sum }}\right)$ depicts the power of a need in the system. The higher the quotient, the more active the need, and in turn, the lower the quotient, the more is the need reactive to others. To calculate how much influence at all a need has in the system, we calculate the product active sum * passive sum. The higher the product is, the more involved is the need in relation to the other needs (critical character). The lower the product is, the less is the need involved in the relation (buffering character). The CIM enables to characterize needs on the dimensions: active $v s$. reactive and critical vs. buffering [64]. Product and quotient are independent from each other (see figure 3 ).

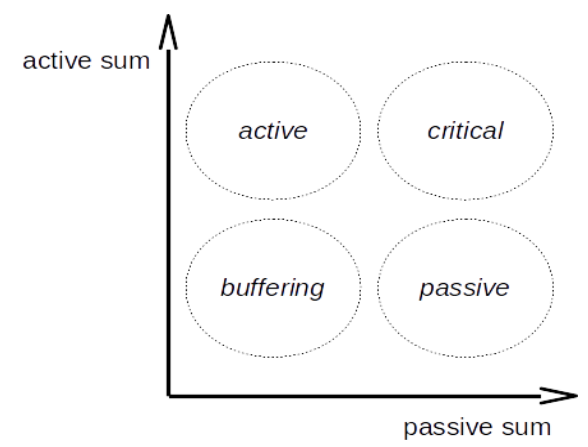

Figure 3: Need dimensions as result of the CIM

To apply the CIM in a Bewextra process, we ask key players in the organization (e.g. decision makers) to fill out a CIM to assess the relation of all needs between each other. Afterwards, we average the results of all CIMs and calculate the product and quotient of the active and passive sum. The quotient or active/reactive dimension depicts $S_{1}$, whereas the product or critical/buffering dimension depicts $S_{2}$ in the measure described below. Vester [64] argues that elements which are active-buffering (upper-left) have a high leverage and, after changing, will stabilize the system again. This could point at needs which should be prioritized in an organizational learning process.

\subsection{Calculating the Bewextra Need Priority Index (BNPI)}

The BNPI covers three views, i.e. internal view $(I)$, external view $(E)$, systemic view $(S)$, and includes several measurements. All three views can be combined into one formula (BNPI) which is illustrated below. A need is only being considered for further investigation iff $I_{0}$ (which reflects the acceptance rate of a need) exceeds a threshold reflected by $\mathrm{x}$. The weights (depicted by values $\alpha$ to $\zeta$ ) can be adjusted flexibly and allow decision maker to reflect their preferences and strategy. The possibility to adjust these weights allows to simulate multiple scenarios. In the following, we present the formula for BNPI and a brief summary of the respective views and factors.

$$
\mathbf{B N P I}= \begin{cases}{\left[\alpha * E_{1}+\beta^{*} E_{2}\right]+\left[\gamma^{*} I_{1}+\delta^{*} I_{2}\right]+\left[\varepsilon^{*} S_{1}+\zeta * S_{2}\right]} & I_{0} \geq x \\ 0 & I_{0}<x\end{cases}
$$


Internal View:

- $\quad I_{0}$ : Level of acceptance (online survey, Bewextra Validation)

- $\quad I_{1}$ : Importance (ranking)

- $I_{2}$ : Urgency (level of current need satisfaction; gap)

External View:

- $\quad E_{1}$ : Importance (ranking performed by analysts)

- $E_{2}$ : "Surface calculation" of need clusters

Systemic View:

- $S_{1}$ : CIM, quotient $\frac{\text { active sum }}{\text { passive sum }}$

- $\quad S_{2}$ : CIM, product active sum * passive sum

We assess all variables on separate scales. In order to combine them, we normalize and re-scale all data points $(P)$ to a common scale from 1 to 10 . Rescaling does not impair the relative distances of data points on their original scales. These values do not indicate the minimum/maximum value possible, rather 1 reflects the minimum, 10 the maximum value assessed within the respective dimension in the dataset. The higher the value, the higher is the respective priority of the need. Consequently, we proceed as follows:

$$
\begin{aligned}
& P_{\text {new }}=\left(\frac{P-N}{M-N}\right) *(T-Q)+Q \\
-\quad \mathrm{P} & =\text { original value } \\
- & \mathrm{N}=\text { Minimum (data point) of original scale } \\
- & \mathrm{M}=\text { Maximum (data point) of original scale } \\
- & \mathrm{Q}=\text { Minimum of new scale }(=1) \\
- & \mathrm{T}=\text { Maximum of new scale }(=10)
\end{aligned}
$$

\section{Empirical findings}

\subsection{Project with the Austrian Federal Economic Chamber}

In May 2016, we carried out an action research project with the scientific board of the Institute for Applied Business Research, a part of the Austrian Federal Economic Chamber. Applying Bewextra, we aimed to uncover the shared needs of its 13 board members. In Bewextra-Collect participants reported 85 satisfiers. In Bewextra-Analytic, analysts derived 6 hypothesis about needs from these satisfiers. In Bewextra-Validation, an online questionnaire was sent out to the participants aiming at validating our hypotheses about underlying needs. In this, we asked participants to express their degree of consent to our hypotheses about their needs on a four-point Likert scale. We weighted the answers "I agree with 100\%;
"I rather agree with 75\%; "I rather not agree with 25\% and "I do not agree" with $0 \%$. Overall, the participants greatly accepted the need hypothesis (see table 2).

\begin{tabular}{|l|l|}
\hline Need & $\begin{array}{l}\text { Acceptance } \\
\text { rate }\left(\boldsymbol{I}_{\boldsymbol{o}}\right)\end{array}$ \\
\hline Networking and cooperation & $90 \%$ \\
\hline Relevance and immediate impact & $94 \%$ \\
\hline $\begin{array}{l}\text { Research-promoting framework } \\
\text { conditions }\end{array}$ & $92 \%$ \\
\hline $\begin{array}{l}\text { Experimental and interdisciplinary } \\
\text { research }\end{array}$ & $90 \%$ \\
\hline Concrete themes/subjects & $90 \%$ \\
\hline Recognition and appreciation & $77 \%$ \\
\hline
\end{tabular}

Table 2: Acceptance rate in Bewextra-Validation

\section{Internal view of the system $\left(I_{1} \& I_{2}\right)$}

In this view, we assessed two aspects. Firstly, we asked participants to rank the identified needs according to their perceived importance $\left(I_{1}\right)$. The results were averaged and normalized resulting in a value from 1 (lowest, perceived as least important) to 10 (highest, perceived as most important).

Secondly, we assessed the gap between current and desired need satisfaction and asked participants to what extent the respective need is currently satisfied $\left(I_{2}\right)$. Again, we averaged the results and normalized them to a scale from 1 to 10 where the highest value corresponds with the largest degree of satisfaction (see table 3).

\begin{tabular}{|l|l|l|}
\hline Need & $\boldsymbol{I}_{\boldsymbol{1}}$ & $\boldsymbol{I}_{\boldsymbol{2}}$ \\
\hline Networking and cooperation & 10,00 & 4,86 \\
\hline $\begin{array}{l}\text { Relevance and immediate } \\
\text { impact }\end{array}$ & 6,68 & 6,40 \\
\hline $\begin{array}{l}\text { Research-promoting framework } \\
\text { conditions }\end{array}$ & 9,05 & 10,00 \\
\hline $\begin{array}{l}\text { Experimental and } \\
\text { interdisciplinary research }\end{array}$ & 7,63 & 5,37 \\
\hline Concrete themes/subjects & 6,92 & 4,60 \\
\hline Recognition and appreciation & 1,00 & 1,00 \\
\hline
\end{tabular}

Table 3: Results of the internal view

\section{External view of the system $\left(E_{1} \& E_{2}\right)$}

In this view, we assessed two aspects. Firstly, data analysts, involved in Bewextra-Analytic ranked the needs according to their subjective experience $\left(E_{l}\right)$. To 
allow for comparison and with other values, the results were normalized to a scale from 1 to $10 . E_{1}$ is comparable to $I_{2}$ of the internal view.

The second aspect $\left(E_{2}\right)$ depicts the relative 'width' and 'depth' of a need cluster. A need cluster with very diverse codes (width) and very similar codes (depth) in total, results in a higher number as there will likely be more scope for action (see table 4).

\begin{tabular}{|l|l|l|}
\hline Need & $\boldsymbol{E}_{\boldsymbol{1}}$ & $\boldsymbol{E}_{\boldsymbol{2}}$ \\
\hline Networking and cooperation & 10,00 & 6,31 \\
\hline $\begin{array}{l}\text { Relevance and immediate } \\
\text { impact }\end{array}$ & 8,20 & 10,00 \\
\hline $\begin{array}{l}\text { Research-promoting framework } \\
\text { conditions }\end{array}$ & 7,30 & 4,83 \\
\hline $\begin{array}{l}\text { Experimental and } \\
\text { interdisciplinary research }\end{array}$ & 2,80 & 4,10 \\
\hline Concrete themes/subjects & 1,00 & 1,00 \\
\hline Recognition and appreciation & 1,00 & 5,50 \\
\hline
\end{tabular}

Table 4: Results of the external view

\section{Systemic view of the system $\left(S_{1} \& S_{2}\right)$}

The third view analyses the perceived effects of a specific need on other relevant needs within the system. We asked four decision makers within the institute to fill out the CIM. We averaged the values and calculated active and passive sum. Firstly, we calculated the quotient from these sums and normalized them to a scale from 1 to 10 . A higher quotient represents a more active and therefore promising need $\left(S_{l}\right)$.

Secondly, the product sum $\left(S_{2}\right)$, was calculated to assess the criticalness of the respective need. A critical need was rated high whereas a buffering was rated low (see table 5).

\begin{tabular}{|l|l|l|}
\hline Need & $\boldsymbol{S}_{\boldsymbol{I}}$ & $\boldsymbol{S}_{\boldsymbol{2}}$ \\
\hline Networking and cooperation & 1,33 & 10,00 \\
\hline Relevance and immediate impact & 1,74 & 8,53 \\
\hline $\begin{array}{l}\text { Research-promoting framework } \\
\text { conditions }\end{array}$ & 4,22 & 4,47 \\
\hline $\begin{array}{l}\text { Experimental and } \\
\text { interdisciplinary research }\end{array}$ & 1,00 & 8,80 \\
\hline Concrete themes/subjects & 10,00 & 1,00 \\
\hline Recognition and appreciation & 2,79 & 3,32 \\
\hline
\end{tabular}

Table 5: Results of the systemic view

\section{Combined views (BNPI)}

Finally, the six normalized values were added up for each need. In this project, we applied identical weighting (1/6) for all values. The BNPI is the result of the weighted and added evaluation of the respective need. It ranges from 1 (lowest) to 10 (highest) and indicates which needs are likely of a higher priority for the organization (see table 6).

\begin{tabular}{|l|l|}
\hline Need & BNPI \\
\hline Networking and cooperation & 7,08 \\
\hline Relevance and immediate impact & 6,93 \\
\hline $\begin{array}{l}\text { Research-promoting framework } \\
\text { conditions }\end{array}$ & 6,65 \\
\hline $\begin{array}{l}\text { Experimental and interdisciplinary } \\
\text { research }\end{array}$ & 4,83 \\
\hline Concrete themes/subjects & 4,09 \\
\hline Recognition and appreciation & 2,44 \\
\hline
\end{tabular}

Table 6: Results of the case study (overall)

\subsection{Ongoing projects}

So far, we applied the BNPI in two other case studies in substantially larger organizations $(\mathrm{N}=41$ and $\mathrm{N}=74$ respectively). Experiences from these cases indicate that the dimensions within the BNPI stay the same. Consequently, the BNPI can be successfully applied in larger social systems and different domains. Project partners valued the results as very useful to decide on next steps to be taken.

\section{Discussion and conclusion}

In this paper we outlined a weighted additive index (BNPI) to prioritize previously identified needs. Applied to organizational learning, the BNPI gives recommendations for strategic decision making and innovation processes based on prioritized need knowledge.

\subsection{Implications for theory and practice}

This paper provides a decision support system which considers an internal, external and systemic view to enhance validated need knowledge. It contributes a systems-thinking perspective to the debate regarding the prioritization of previously identified needs. It is, to the best of our knowledge, the first conceptual work that outlines the prioritization of need knowledge explicitly from a system-theoretical perspective.

From a practitioner's point of view, the weighted additive index should leverage decision making within different kinds of organizations. As our project with an institute of the Austrian Federal Economic Chamber 
showed, it provides decision makers with a guideline and recommendation for strategic managerial decisions in innovation contexts (i.e. what to do next and where to allocate scarce resources). Enhanced need knowledge could also guide the development of new products, services and solutions that helps organizations to be sustainably successful in the future.

\subsection{Limitations and future research}

The framework might have to be slightly adapted for different domains and even larger kinds of organizations. Even though initial feedback from the project partner was positive, we cannot estimate the benefit for decision making processes in the organization itself at this point of time. In addition, we acknowledge the possibility that the list of submeasurements we assessed might not be exhaustive (i.e. we missed an important dimension we are not aware of). Another limiting factor might be the different scale types of the data assessed (ranked variables and ordinal-scaled variables).

Based on promising results from the case study and the limitations mentioned above, further research should focus on implementing, analysing and evaluating further applications of the Bewextra Need Priority Index (BNPI) with other organizations and, if necessary, adapting the framework. Further work should also explore possibilities to develop a visual representation of prioritized needs as suggested in [6].

\section{References}

[1] B. L. Bayus, "Understanding Customer Needs," in Handbook of Technology and Innovation Management, S. Shane, Ed. New York: John Wiley \& Sons, 2008, pp. 115142.

[2] M. Van Der Brouwer and K. Dorst, "How deep is deep? a four-layer model of insights into human needs for design innovation," in Proceedings of the Colors of Care: The 9th International Conference on Design \& Emotion, 2014, pp. 280-287.

[3] A. Ericson and A. Stahlbrost, "In Search of Innovation," Int. J. Technol. Knowl. Soc., vol. 2, 2006.

[4] K. Holt, "Need Assessment in Product Innovation," Int. Stud. Manag. Organ., vol. 6, no. 4, pp. 26-44, 1976.

[5] D. Patnaik and R. Becker, "Needfinding: The Why and How of Uncovering People's Needs," Des. Manag. J., vol. 10, no. 2, pp. 37-43, 1999.
[6] E. von Hippel and G. Von Krogh, "CROSSROADS - Identifying Viable 'Need-Solution Pairs': Problem Solving Without Problem Formulation," Organ. Sci., vol. 27, no. 1, pp. 207-221, 2016.

[7] A. Kaiser and F. Kragulj, "Bewextra: Creating and Inferring Explicit Knowledge of Needs," J. Futur. Stud., vol. 20, no. 4, pp. 79-98, 2016.

[8] D. Patnaik, "System Logics: Organizing Your Offerings to Solve People's Big Needs," Des. Manag. Rev., vol. 15, no. 3, pp. 50-57, 2004.

[9] A. W. Ulwick, "Turn Customer Input into Innovation," Harv. Bus. Rev., vol. 80, no. 1, pp. 91-97, 2002.

[10] A. Kaiser, B. Fordinal, and F. Kragulj, "Creation of Need Knowledge in Organizations: An Abductive Framework," in 47th Hawaii International Conference on System Sciences, 2014, pp. 3499-3508.

[11] A. Kaiser, F. Kragulj, and T. Grisold, "Taking a Knowledge Perspective on Needs: Presenting Two Case Studies Within an Educational Environment in Austria," Electron. J. Knowl. Manag., vol. 14, no. 3, pp. 114-126, 2016.

[12] K. Goffin, F. Lemke, and U. Koners, Identifying Hidden Needs. London: Palgrave Macmillan, 2010.

[13] K. Goffin and F. Lemke, "Uncovering your customer's hidden needs," Eur. Bus. Forum, no. 18, pp. 45-47, 2004.

[14] J. W. Altschuld and R. Watkins, "A primer on needs assessment: More than 40 years of research and practise," in New Directions for Evaluation, Needs asse., vol. 144, J. W. Altschuld and R. Watkins, Eds. 2014, pp. 518.

[15] J. Altschuld and N. Eastmond, Needs Assessment. 2010.

[16] D. Bawden and L. Robinson, "The dark side of information: overload, anxiety and other paradoxes and pathologies," J. Inf. Sci., vol. 35, no. 2, pp. 180-191, 2009.

[17] D. Gasper, "Conceptualising human needs and wellbeing," in Wellbeing in Developing Countries, I. Gough and J. MacGregor, Eds. Cambridge: Cambridge University Press, 2007, pp. 47-70.

[18] D. Gasper, "Needs and Basic Needs: a Clarification of Meanings, Levels, and 
Different Streams of Work.” pp. 1-40, 1996.

[19] A. H. Maslow, Motivation and personality, 2nd ed. New York: Harper \& Row, 1970.

[20] A. Maslow, "A Theory of Human Motivation," Psychol. Rev., vol. 50, no. 4, pp. 370-396, 1943.

[21] D. Braybrooke, Meeting Needs, vol. 2. Princeton: Princeton University Press, 2014.

[22] L. Doyal and I. Gough, A Theory of Human Need. Houndmills, Basingstoke, Hampshire and London: The Macmillan Press Ltd, 1991.

[23] P. Ekins and M. Max-Neef, "Development and human needs," in Real-Life Economics: Unterstanding Wealth Creation, London: Routledge, 1992, pp. 197-214.

[24] K. Goffin, F. Lemke, and U. Koners, Identifying hidden needs: creating breakthrough products. London: Palgrave Macmillan, 2010.

[25] K. Wiegers and J. Beatty, Software Requirements, Third Edition. Redmond, Washington: Microsoft Press, 2013.

[26] M. E. Pullman, W. L. Moore, and D. G. Wardell, "A comparison of quality function deployment and conjoint analysis in new product design," J. Prod. Innov. Manag., vol. 19, no. 5, pp. 354-364, 2002.

[27] J. Hauser, "How Puritan-Bennett Used the House of Quality," Sloan Manage. Rev., vol. 34, no. 3, pp. 61-70, 1993.

[28] J. Hauser and D. Clausing, "The House of Quality," Harv. Bus. Rev., vol. May-June, 1988.

[29] T. Felin and T. R. Zenger, "CROSSROADSStrategy, Problems, and a Theory for the Firm," Organ. Sci., vol. 27, no. 1, pp. 222231, 2016.

[30] P. Andriani, A. Ali, and M. Mastrogiorgio, "Measuring exaptation and its impact on innovation, search, and problem solving," Organ. Sci., vol. 28, no. 2, pp. 320-338, 2017.

[31] R. Baskerville and M. D. Myers, "Special Issue on Action Research in Information Systems: Making Is Research Relevant To Practice-Foreword," MIS Q., vol. 28, no. 3, pp. 329-335, 2004.

[32] M. A. Wahba and L. G. Bridwell, "Maslow reconsidered: A review of research on the need hierarchy theory," Organ. Behav. Hum. Perform., vol. 15, no. 2, pp. 212-240, 1976.
[33] D. T. Kenrick, V. Griskevicius, S. L.

Neuberg, and M. Schaller, "Renovating the Pyramid of Needs: Contemporary Extensions Built Upon Ancient Foundations.," Perspect. Psychol. Sci., vol. 5, no. 3, pp. 292-314, 2010.

[34] G. Thomson, "Fundamental Needs," R. Inst. Philos. Suppl., vol. 57, pp. 175-186, 2005.

[35] W. W. Cooper and J. T. Pastor, "Global efficiency measurement in DEA," Alicante, Spain, 1995.

[36] W. W. Cooper, K. S. Park, and J. T. Pastor, "RAM: A Range Adjusted Measure of Inefficiency for Use with Additive Models, and Relations to Other Models and Measures in DEA," J. Product. Anal., vol. 11, no. 1, pp. 5-42, 1999.

[37] D. J. Power, R. Sharda, and F. Burstein, "Decision Support Systems," in Wiley Encyclopedia of Management, John Wiley \& Sons, Ltd, 2015, pp. 1-4.

[38] F. Burstein and C. Holsapple, Handbook on Decision Support Systems 1: Basic Themes. Berlin, Heidelberg: Springer, 2008.

[39] R. Yin, Case Study Research Design and Methods. Beverly Hills: Sage Publications, 2013.

[40] K. M. Eisenhardt, "Building Theories from Case Study Research,” Acad. Manag. J., vol. 14, no. 4, pp. 532-550, 1989.

[41] K. Eisenhardt and M. Graebner, "Theory Building From Cases : Opportunities and Challenges," Acad. Manag. J., vol. 50, no. 1, pp. 25-32, 2007.

[42] P. Checkland, Systems Thinking, Systems Practice. Chichester, West Sussex: Wiley \& Sons, 1981.

[43] G. Dominici and G. Levanti, "The Complex System Theory for the Analysis of Inter-Firm Networks. A Literature Overview and Theoretic Framework," Int. Bus. Res., vol. 4, no. 2, pp. 31-38, 2011.

[44] B. Richmond, "Systems thinking: critical thinking skills for the 1990s and beyond," Syst. Dyn. Rev., vol. 9, no. 2, pp. 113-133, 1993.

[45] B. Rubenstein-Montano, J. Liebowitz, J. Buchwalter, D. McCaw, B. Newman, and K. Rebeck, "A systems thinking framework for knowledge management," Decis. Support Syst., vol. 31, no. 1, pp. 5-16, 2001.

[46] M. Yolles, “Organisations, Complexity, and 
Viable Knowledge Management," Kybernetes, vol. 29, no. 9/10, pp. 1202-1222, 2000.

[47] C. Mele, J. Pels, and F. Polese, “A Brief Review of Systems Theories and Their Managerial Applications," Serv. Sci., vol. 2, no. 1-2, pp. 126-135, Jun. 2010.

[48] G. Dominici and G. Levanti, "The Complex System Theory for the Analysis of Inter-Firm Networks. A Literature Overview and Theoretic Framework," Int. Bus. Res., vol. 4, no. 2, pp. 31-38, 2011.

[49] N. Luhmann, Soziale Systeme. Grundriss einer allgemeinen Theorie. Frankfurt am Main: Suhrkamp, 1990.

[50] E. Schwarz, "Can Real Life Complex Systems Be Interpreted with the Usual Dualist Physicalist Epistemology - Or is a Holistic Approach Necessary?," in ResSystemica, Volume $N^{\circ} 2$, Special Issue: Proceedings of the fifth European Systems Science Congress, 2002, pp. 1-9.

[51] C. W. Churchman, "Operations Research as a Profession,” Manage. Sci., vol. 17, no. 2, pp. 37-53, 1970.

[52] M. Yolles, "Viable boundary critique," J. Oper. Res. Soc., vol. 52, no. 1, pp. 35-47, 2001.

[53] W. Ulrich and M. Reynolds, "Critical Systems Heuristics," in Systems Approaches to Managing Change : A Practical Guide, M. Reynolds and S. Holwell, Eds. London: Springer, 2010, pp. 243-292.

[54] G. Midgley, "Science as Systemic Intervention: Some Implications of Systems Thinking and Complexity for the Philosophy of Science," Syst. Pract. Action Res., vol. 16, no. 2, pp. 77-97, 2003.

[55] M. C. Achterkamp and J. F. J. Vos, "Critically identifying stakeholders evaluating boundary critique as a vehicle for stakeholder identification," Syst. Res. Behav. Sci., vol. 24, no. 1, pp. 3-14, 2007.

[56] R. E. Freeman, Strategic management: A stakeholder approach. Mashfield: Pitman Publishing Inc., 1984.

[57] R. E. Freeman, A. C. Wicks, and B. Parmar, "Stakeholder Theory and 'The Corporate Objective Revisited,"” Organ. Sci., vol. 15, no. 3, pp. 364-369, 2004.

[58] W. Ulrich, "Critical heuristics of social systems design,” Eur. J. Oper. Res., vol. 31, no. 3, pp. 276-283, 1987.

[59] O. Scharmer, Theory U: Learning from the future as it emerges. San Francisco: BerrettKoehler Publishers, 2009.

[60] F. Kragulj, "Interacting with the envisioned future as a constructivist approach to learning," Constr. Found., vol. 9, no. 3, pp. 439-440, 2014.

[61] K. Charmaz, Constructing grounded theory: A practical guide through qualitative analysis. London: Sage Publications Limited, 2006.

[62] J. Reichertz, "Abduction: The Logic of Discovery of Grounded Theory," in The Sage Handbook of Grounded Theory, A. Bryant and K. Charmaz, Eds. London: Sage, 2007, pp. 214-229.

[63] F. Kragulj, "A Knowledge Perspective on Needs as a Foundation for Organisational Learning Processes," in Proceedings of the International Conference Theory and Application in the Knowledge Economy (TAKE 2016), 2016, pp. 196-209.

[64] F. Vester, Die Kunst vernetzt zu denken. Stuttgart: DVA, 1999.

[65] T. J. Gordon and H. Hayward, "Initial experiments with the cross impact matrix method of forecasting," Futures, vol. 1, no. 2, pp. 100-116, Dec. 1968.

[66] L. E. Schlange and U. Jüttner, "Helping managers to identify the key strategic issues," Long Range Plann., vol. 30, no. 5, pp. 777786, 1997. 